\title{
Psychometric Properties from Geriatric Social Work Competencies Scale II
}

\author{
Rubio A. Suarez \\ University of Luterana Salvadorena, El Savador \\ Email: rubio.a77@gmail.com
}

\begin{abstract}
The Geriatric Social Work Competencies Scale II (GSWCS II) is considered a reference in the assessment of the competencies of Gero Social Workers. The aim of the study is to examine the psychometric properties of GSWCS II in a sample of Portuguese social workers work-ing with elderly people. The GSWCS II was administered in conjunction with a specific designed socio-professional questionnaire. A total of 543 social workers were interviewed, with a mean age of $33.05(7.57=S D)$, female $(96.1 \%)$ and in management functions $(72.5 \%)$. Internal consistency was verified with high values in all dimensions $(\alpha>9)$. The scale has high correlations with all its dimensions (> 85). The Confirmatory Factor Analysis was used to test the model, based on a five-dimensional structure, the chi-square test of adjustment $\left(x^{2} / d f\right)=3.129$ presented an acceptable index of adjustment. The GSWCS II proved to be a valid and reliable scale for this population.
\end{abstract}

Keywords: Social work, Elderly People, Competencies.

\section{A. INTRODUCTION}

Second to United Nations, in 2015, 901 thousand people have 60 years or more (12\% of the global population), presenting this universe with a growth tax of 3.26 years (2015). Not ranking two continents is Europe that had a higher percentage of population with 60 years or more (24\%), yet estimates that the near future will be a rapid growth in other parts of the world. In 2050 and expect that the main regions of the world, except Africa, have almost a quarter or more of its population with 60 years or more. It is estimated that the number of people in the world will be 2.1 billions in 2050 and could rise to 3.2 billions in 2100 (United Nations, Department of Economic and Social Affairs, 2015).

A population with more than 60 years or a subset that has increased the most is or two older people, with 80 or more years of age. This will increase significantly, from 125 thousand in 2015 to 434 thousand in 2050 and 944 thousand in 2100, with 28\% living in Europe in 2015, resulting in this percentage decrease to $16 \%$ in 2050 and 9\% in 2100. In counterpart as Populations of other areas of the world will continue, proportionally, to increase from the size of their own to the larger (United Nations, Department of Economic and Social Affairs, 2015).

This new scenario of hurried transformations has been verified by demographers, also important alterations in the composition of two family aggregates, 
which have repercussions in the family relationships between the various generations and, consequently, in the older generations. The family aggregates, characterized, have been little time, by an intergenerational coexistence, gradually giving rise to "new family arrangements, even though the house with children remains as the parent of the dominant organization, registers-will remain light of its frequency, parallel to a relative increase in single-parent families and single parent families" (Campos \& Teixeira, 2010); Correlated with these changes, there is an increasingly greater mobility of two geographical and socio-professional itineraries, a growing participation of women in the labor market, new rhythms of life that have impacts not on the family and social framework of idle people.

As a result of these transformations, various professions, among the four social assistants, are summoned to respond to the needs of this growing population. Second Scharlach, Damron-Rodriguez, Robinson and Feldman (2000) these technicians can trace unique contributions both to idle people and to their families. Not in the same sense Tuncay and Duyan, in the path of Scharlach, Damron-Rodriguez, Robinson and Feldman (2000), affirmed that "in the need of social assistants with knowledge".

Gerontology is based on the conviction that the values of the profession, the theoretical perspectives and the competencies are essential to love or be happy with two families (Tuncay \& Duyan, 2015).

Literature reports that there are several factors that contribute to the development of gerontological competencies not Social Service (Gleason-Wynn, 1996; Rosen et al., 2000; Scharlach et al., 2000). Second Rosen et al. (Rosen et al., 2000), or the increase in the large population and diversity of growth justifies the insertion of gerontological content in the Social Service curriculum. List, also, at the expense of social assistants with knowledge and skills required to satisfy the needs of the large population. Let us recall a research carried out in the United States, with members of the National Association of Social Assistants (NASW) that demons-trou, by extrapolation, that $26 \%(29,650)$ two social assistants work normally with a large population and that two social assistants that they do not work, $62 \%$, referem that or gerontological knowledge is necessary to us their positions of work (Gleason-Wynn, 1996). It is acknowledged that in the near future this need will be even more important, and for that reason, it is suggested to introduce curricular content in this area (Peterson, 1990). As gerontological competencies, second Hooyman (2009), are fundamental to guarantee that all social assistants are prepared to work with adults more aged, one time more than one interaction of some form with that population. In the same way, it is necessary to have advanced gerontological competencies for geriatric specialized practice and professional leadership in this expanding field (Hoyman, 2009).

In 2004, the United States of America, or Council on Social Work Education (CSWE), Commission for Curriculum and Educational Innovation (COCEI) and 
Commission for Accreditation (COA) initiate the process of analysis and revision of Educational Policy and Accreditation Standards (EPAS). After an extensive work that includes a review of the literature and the opinions of specialists, we will identify several pillars that will guide this process. In order to reformulate the Educational Policy and Accreditation Standards based on the results of two students, only the behavior of practice, or what a student should learn and be able to do, lead to an educational approach based on competencies (CSWE, 2008). It is based on this philosophy that arose from the Geriatric Social Work Competencies Scale that it is considered as a set of "skills recognized by gerontological social assistants as important for social assistants who work effectively as an adult on behalf of more old people and their families "(CSWE, 2008). On the aforementioned scale, which counted as support for not so much development of the Council on Social Work Education, CSWE.

Gero-Ed Center Competency Goals as do Hartford Partnership Program in Aging Education, HPPAE, started with a comprehensive review of the literature on Social Service Gerontology, producing set of 128 a possible professional skills. Copy of two 128 items was sent to academic consultants specialized in gerontology, researchers and professionals. This panel of specialists was invited to evaluate the items and suggest suppressions, additions and modifications. A pre-test was, followed, sent to the social assistants. Based on the recommendations of the panel and of the pre-test, 65 items identified related to three major professional domains: (i) Knowledge about idle individuals and their families (17 items); (ii) Professional Skills (32 items); (iii) Professional practice (16 items). A post to review two items relative to redundancy, clarity and specificity for gerontological practice, pre-tested and endorsed for am and a sample of convenience. The final questionnaire was distributed to 2,400 social assistants, teachers and researchers. On a scale, there are developments with elimination of items and an increase in a new subscale. Two studies that give account of some psycho-metric properties or that are close to the study that we intend to do was carried out by Tuncay \& Duyan (2015) as a group of students of Bachelor of Social Work in Turkey.

In this article we will present the psychometric characteristics of the Geriatric Social Work Competencies Scale II administered by a number of Portuguese social assistants who work with idle people.

\section{B. METHOD}

We use this research in addition to a questionnaire of socio-professional characterization, prepared by us, to the Geriatric Social Work Competencies Scale II. A Geriatric Social Work Competencies II Scale is made up of 50 items that are subdivided into different domains: (i) Ethics and theoretical perspectives, Specialized competition (I carry out this competition with enough to teach others). 
Appropriate permission to use the scale, start or process of translation and adaptation of the instrument to the Portuguese version, it is important to initiate or process that would allow the use of scale by native Portuguese language. The process completed six phases: (1) Translation of the instrument; (2) Retroversion, (3) Evaluation of dissimilarities, (4) Retroversion of dissimilar items, (5) Test-pilot and (6) Study of reliability (internal consistency) and validated.

Not that it concerns an empirical study, which allows us to collect the data presented here, this initiation has led to the obtaining, from the Social Charter, two electronic straights of institutions in mainland Portugal, with social responses aimed at advancing progress (Centro de Social, Day Center, Night Center, Residential Structure for the Elderly and Home Support Service). 3,615 institutions were identified and contacted via email. No body of the message, as well as the description of the study, was also sent or a link that refers to an online form, made available through Google Docs electronic hardware.

In the analysis and statistical treatment we use SPSS (Statistical Package for Social Sciences, version 24) and the optional software AMOS (Analysis of Moment Structures, version 18.0). In the first phase, we performed an analysis of two items through the internal consistency (Cronbach's Alpha), the Pearson correlation coefficient was used to verify the correlation between the scale of these dimensions. A Confirmatory Analysis was also carried out to verify its tested model, based on a fivedimensional structure, it found good adjustment indices. The global adjustment quality of the factorial model was evaluated according to the following indices: o Qui-squared adjustment test $\left(\chi^{2} / \mathrm{gl}\right)$, o Comparative Fit Index (CFI) eo Root Mean Square Error of Approximation (RMSEA, P [rmsea $\leq 0.05]$ ). The quality of the local adjustment was assessed by factorials weights.

Participants

The participants were mostly female $(n=513 ; 96.1 \%)$ communities comprised between 22 and 63 years of age, with an average age of $35.05 \pm 7.56$. Two more participants started their training in private teaching establishments ( $\mathrm{n}=387 ; 72.5 \%)$, they finished their training in $2007(n=53$; 9.9\%), was "Principal Social Assistant" ( $n=$ $114 ; 21.3 \%), 332(85.8 \%)$ assumed positions of chief and worked mainly in Social Solidarity Associations ( $n=234 ; 43.8 \%)$.

\section{RESULT AND DISCUSSION}

The Cronbach's alpha calculation revealed that both the Geriatric Social Work Competencies Scale II and its dimensions show a consistency internal elevated (Cronbach's $\alpha>0.902$ ) respecting the criteria described in the literature (Daniel, Gomes, \& Ferreira, 2015; Peterson, 1994). 
Table 1 Internal Consistency of Scale

\begin{tabular}{|l|c|c|}
\hline \multicolumn{1}{|c|}{ GSWS II } & $\begin{array}{c}\text { Alpha of } \\
\text { Cronbach }\end{array}$ & $\begin{array}{c}\text { Number of } \\
\text { items }\end{array}$ \\
\hline I. Values, Ethics and Theoretical Perspectives & .979 & 50 \\
\hline II. Appraisal & .902 & 10 \\
\hline III. Intervention & .902 & 10 \\
\hline IV. Services, programs and policies aging & .924 & 10 \\
\hline V. Leadership in the context of work with people elderly & .946 & 10 \\
\hline
\end{tabular}

The correlations between Geriatric Social Work Competencies II and its dimensions are high, statistically significant, with values higher than 815 .

Table 2 Correlations between the Global Scale and its dimensions $(n=534)$

\begin{tabular}{|c|c|c|c|c|c|c|}
\hline & I & II & III & IV & V & GSWS \\
\hline I. Values, Ethics and Perspectives Theoretical & - & $.724 *$ & $.737 *$ & $.637 *$ & $631 *$ & $.815^{*}$ \\
\hline II. Appraisal & & - & $.792 *$ & $.689=$ & $.643^{*}$ & $.856^{\prime \prime}$ \\
\hline III. Intervention & & & - & $.819 *$ & $.760^{*}$ & $.927^{*}$ \\
\hline IV. Services, programs and Aging policies & & & & - & $.829 *$ & $.915 *$ \\
\hline V. Leadership in the context of I work with elderly people & & & & & - & $.895 *$ \\
\hline GSWS II & & & & & & - \\
\hline
\end{tabular}

** A correlation and significant non-level .01 (bilateral).

The lowest factorials weights (table 4), will vary between a minimum of 583 (item 1 of the Values, Ethics and theoretical perspectives dimension) and a maximum of 862 (item 7 «Development services, programs and policies» and item 3 "Leadership in the context of work with elderly people "with equal scores).

Table 3 Regression weights standardized two items of the GSWS II dimensions

\begin{tabular}{|c|c|c|c|c|c|}
\hline Items & $\begin{array}{c}\text { Values, Ethics } \\
\text { e perspectives } \\
\text { theoretical }\end{array}$ & Appraisal & Intervention & $\begin{array}{c}\text { Services, } \\
\text { programs and } \\
\text { policies of } \\
\text { aging }\end{array}$ & $\begin{array}{c}\text { Leadership no } \\
\text { context of } \\
\text { I work with } \\
\text { elderly weights }\end{array}$ \\
\hline Item 1 & .583 & .688 & .645 & .680 & .740 \\
\hline Item 2 & .699 & .724 & .721 & .748 & .787 \\
\hline Item 3 & .707 & .784 & .732 & .788 & .862 \\
\hline Item 4 & .649 & .734 & .777 & .778 & .850 \\
\hline Item 5 & .659 & .733 & .802 & .808 & .854 \\
\hline Item 6 & .724 & .797 & .791 & .859 & .870 \\
\hline Item 7 & .731 & .739 & .814 & .862 & .855 \\
\hline Item 8 & .762 & .666 & .790 & .804 & .858 \\
\hline Item 9 & .655 & .761 & .698 & .810 & .848 \\
\hline Item 10 & .779 & .742 & .705 & .840 & .853 \\
\hline
\end{tabular}


The model, as can be observed in Table 1, was tested through a Factorial Confirmatory Analysis. It is based on a five-monthly structure (inter-correlation matrix with 50 items), from the Geriatric Social Work Competencies Scale II. The adjustment indices for the GSWCS are compatible with a five-dimensional model. According to the Confirmatory Factorial Analysis, or Qui-square of adjustment $\left(\chi^{2} / \mathrm{gl}\right)=3.129$ to present an adequate adjustment, in all indices (RMSEA $=.064, \mathrm{CFI}=.97, \mathrm{GFI}=.890$ and TLI $=.883$ ) have an oil fit for a five-dimensional model.

The new challenges of the growth of the population and the consequent opening of new fields of professional action years / members assistants call us to reflect on the technical competencies in this area. A need for competencies are assimilated to literature, or a study by Naito-Chan, Damron-Rodriguez \& Simmons (2004) carried out with four focus-groups of idle adults, caregivers (consumers), entrepreneurs in the field of development and recently licensed in Illustrative Social Service. Several competencies formed relatively years/to social assistants, not only to identification of resources, to capacity to carry out geriatric evaluations, to case management, to capacity of self-awareness. I have many «consumers» not understanding the role of two social assistants. The focus of competencies in technical training is considered a path. The importance of competencies is also reported by Tuncay \& Duyan (2015) supported by Naito-Chan, Damron-Rodriguez \& Simmons (2004) "a personal competence (such, knowledge and skills) in the provision of adequate services, it is considered a primary indicator of organizational quality and a key for obtaining credentials".

\section{CONCLUSION}

This study also makes the academic and professional community aware of the existence of the Geriatric Social Work Competencies Scale II that maps the competencies recognized as important for all social assistants who work with idiosyncratic people, examines their suas Psychometric properties from two results obtained in a sample of social assistants who work with idiosyncratic people in Portugal. A Geriatric Social Work Competencies Scale II shows reliability coefficients - internal consistency -, measured by Cronbach's alpha, considered high, as is not the study by Tuncay \& Duyan (2015). The correlation coefficients between the dimensions on the scale are equally high. Factorial weights are greater than 6 tenths in all items. The indexes of fit adjustment between good and reasonable indo year found two presented by Tuncay and Duyan (2015) as a scale with four dimensions. Analyzing the results obtained, we can affirm that this instrument has adequate psychometric qualities and in this way can be used to determine the self-assessed competition of our basic and specialized behaviors of two social assistants. 


\section{REFERENCES}

1. Campos, M. S., \& Teixeira, S. M. (2010). Gênero, família e proteção social: as desigualdades fomentadas pela política social. Revista Katálysis, 13(1), 20-28.

2. CSWE. (2008). Advanced Gero Social Work Practice. CSWE Gero-Ed Center/Council on Social Work Education (CSWE).

3. Hooyman, N. R. (2009). Transforming Social Work Education: The First Decade of the Hartford Geriatric Social Work Initiative. Council on Social Work Education. 1701 Duke Street Suite 200, Alexandria, VA 22314.

4. Naito-Chan, E., Damron-Rodriguez, J. \& Simmons, W. J. (2004). Identifying Competencies for Geriatric Social Work Practice. Journal of Gerontological Social Work, 43(4), 59-78.

5. Gleason-Wynn, P. E. (1996). Addressing the educational needs of nursing home social workers. Gerontology E Geriatrics Education, 16(2), 31-36.

6. Scharlach, A., Damron-Rodriguez, J., Robinson, B. \& Feldman, R. (2000).Educating social workers for an aging society: A vision for the 21st century. Journal of Social Work Education, 36(3), 521-538.

7. Tuncay, T. \& Duyan, V. (2015). Turkish Adaptation of the Geriatric Social Work Competency Scale in a Group of Social Work Bachelor Students. Turkish Journal of Geriatrics, 18(1), 60-67.

8. United Nations, Department of Economic and Social Affairs, P. D. (2015). World Population Prospects: The 2015 Revision, Key Findings and Advance Tables (241 No. ESA/P/WP). 